\section{Prestressed concrete targets under high rate of loading}

\author{
Abhishek Rajput', Mohammad Ashraf Iqbal' \\ and Chengqing $\mathrm{Wu}^{2}$
}

International Journal of Protective Structures

2018, Vol. 9(3) 362-376

(C) The Author(s) 2018

Article reuse guidelines:

sagepub.com/journals-permissions

DOI: |0.1|77/204|4|96|8763933

journals.sagepub.com/home/prs

(S)AGE

\begin{abstract}
Prestressed concrete is highly being preferred as material for construction in the case of strategic and relevant structures such as, for instance, nuclear containments, armor deposits, shelters, bridges, and military bunkers. It is highly durable, fire and corrosion resistant, and non-porous. In order to study the influence of prestressing on the mechanics of deformation, energy absorption capacity, and failure modes of concrete targets, finite element simulations have been carried out using hard steel bullets and compared with the experiments carried out by the authors earlier. Prestressed concrete targets of plan size $450 \mathrm{~mm} \times 450 \mathrm{~mm}$ and thickness of $80 \mathrm{~mm}$ were impacted by $0.5-\mathrm{kg}$ hard steel projectiles. The concrete was designed to obtain an unconfined compressive strength of $48 \mathrm{MPa}$. An initial stress of $10 \%$ magnitude of compressive strength was induced by 4 -mm-diameter high-tensile-strength $(1700 \mathrm{MPa})$ steel wires in prestressed concrete targets. A grid of 8-mm-diameter steel bars was inserted in the reinforced and prestressed concrete targets to enable the straight comparison between these concretes. The prestressing in concrete has been found to be effective in reducing the volume of scabbed material as well as the ballistic resistance of prestressed concrete targets. The ballistic limit of prestressed concrete with $10 \%$ induced stress was found to be, respectively, $14 \%$ higher than that of the plain concrete target and $10.2 \%$ higher than the reinforced concrete. Failure modes predicted through finite element simulations were found in agreement with that of the actual results.
\end{abstract}

\title{
Keywords
}

Prestressed concrete, perforation, failure modes, scabbing, ballistic resistance

\section{Introduction}

The study of ballistic characteristics of plain and reinforced concrete is extremely important in order to design the important strategic structures such as nuclear containment, bunkers, bridges, and dams. The penetration mechanism of concrete barrier is relatively more complex than the metals due to its complex material behavior. During modern decades the study of the response of plain or reinforced concrete targets under ogive-nosed projectile impact has been enhanced by a number

\footnotetext{
'Department of Civil Engineering, Indian Institute of Technology Roorkee, Roorkee, India

${ }^{2}$ Centre for Built Infrastructure Research, School of Civil and Environmental Engineering, University of Technology Sydney, Sydney, NSW, Australia
}

\section{Corresponding author:}

Abhishek Rajput, Department of Civil Engineering, Indian Institute of Technology Roorkee, Roorkee 247677, India.

Email: hiitsme.abhishek@gmail.com 
of experimental and analytical works (Forrestal et al., 1994; Li et al., 2005; Warren et al., 2004, 2014; Wen and Yang, 2014).

A consistent improvement in strength and performance over last few decades transformed the concrete into most suitable construction material worldwide. Hanchak et al. (1992) carried out ballistic experiments on 48 and $140 \mathrm{MPa}$ reinforced concrete targets of plan size $(610 \mathrm{~mm} \times 610 \mathrm{~mm})$ and $178-\mathrm{mm}$ thickness against ogival-nosed $0.5-\mathrm{kg}$ projectiles. The concrete targets were reinforced by three layers of 5.69-mm-diameter steel reinforcement grid. They established that even an intensification of the compressive strength by around three times had no significant influence on the resistance of the target respect to impacts. In contrast with that, the ballistic experiments carried out by Shirai et al. (1997) on targets realized by 35 and $57 \mathrm{MPa}$ reinforced concrete provided clear evidences on the fact that material strength has a major role to halt the penetration of the projectile and to limit the effect of scabbing in the material. Hanchak et al. (1992) verified that an almost negligible effect on the residual velocities can be related to the reinforcement. However, Liu and Ning (2009) suggested that the capacity of reinforced concrete carrying dynamic loads is significantly related to the magnitude of reinforcement, explaining why targets in plain concrete performed worse than the ones in reinforce concrete at higher ratios of reinforcement and the opposite occurred at low ratios. A mesoscale material model for concrete at was developed to simulate the impact test to evaluate the dynamic material properties of concrete at high strain rate (Hao et al., 2010). Adhikary et al. (2015) have performed experiments and numerical simulation of drop-weight test on reinforced concrete beams to study the response of failure modes with increasing drop-weight height.

The dynamic crack propagation and impact load carrying capacity of prestressed concrete railway sleepers at varying support conditions and rate of loading (Kaewunruen and Remennikov, 2009, 2010, 2011; Xiang and Nianzhi, 1994) have been investigated in the cases of single and multiple impact loads. Under hard track condition (ballast thickness of $250 \mathrm{~mm}$ ), the crack length in sleeper was found to be higher and the propagation of crack is faster than in soft track condition (ballast thickness of 100-150 mm). Under both of these support conditions, however, the failure occurred in flexure and longitudinal splitting. The prestressed concrete rock sheds are used in various countries to avoid casualties against falling rocks (Delhomme et al., 2007; Ishikawa et al., 2002). In an investigation of impact response of $T$ - and $\Gamma$-shaped prestressed concrete rock sheds (Delhomme et al., 2007) studied through prototype experiments, the T-shaped frame has been found to rationally disperse the sectional forces over the whole structure and offered 1.7 times more resistance than $\Gamma$-shaped frame. Researches on the capacity of the concrete respect to the blast load resistance clarified that an initial prestressing can have effect on the deflections in concrete elements, reducing them both in maximum and residual terms, and was also found to be effective in delaying the appearance and growth of flexural cracks (Chen et al., 2015). Along this line of investigation, in Pavlovic et al. (2017), several finite element (FE) models were used to provide an accurate discretization of the phenomena related to the projectile impact on reinforced concrete. In particular, to compare the non-linear response of material, several simulations were carried out based on Riedel-Hiermaier-Thoma (RHT) material models available in different commercial finite element method (FEM) codes. The RHT material model, available in LS-DYNA, predicted that the experiments are in agreement, and hence, it was found most suitable model to simulating the projectile impact on concrete targets.

Similar investigations were also realized on other constructive materials, as in Fragassa (2016) and Pavlovic and Fragassa (2016), where a detailed models and FE techniques were compared with the scope at investigating the viscoelastic response in stoneware.

The present investigation aims to explore the possible influence of the initially induced stress on the energy absorption, ballistic response, and failure modes of prestressed concrete target against ogive-nosed projectile impact. The prestressed concrete plates of dimension $(450 \mathrm{~mm} \times 450 \mathrm{~mm} \times 80 \mathrm{~mm})$ were subjected to $0.5-\mathrm{kg}$ ogival-nosed (3 Calibre Radius Head 
Table I. Constituents of concrete.

\begin{tabular}{lllll}
\hline Cement $\left(\mathrm{kg} / \mathrm{m}^{3}\right)$ & W/C ratio & Water $\left(\mathrm{kg} / \mathrm{m}^{3}\right)$ & Aggregate $\left(\mathrm{kg} / \mathrm{m}^{3}\right)$ & Sand $\left(\mathrm{kg} / \mathrm{m}^{3}\right)$ \\
\hline 440 & 0.40 & 180 & 1050.4 & 730 \\
\hline
\end{tabular}

W/C: water/cement.

$(\mathrm{CRH}))$ hard steel projectiles at normal incidence and compared with the experiments carried out in the previous study (Rajput et al., 2017a, 2017b). To further explore the mechanics of deformation, the impact experiments were reproduced through FE simulations. The failure modes, extent of damage, and energy absorption capacity of prestressed concrete target have been obtained through projectile impact experiments and compared with numerical results.

\section{Target preparation}

The concrete mix was realized in accordance with the IS 10262 Indian Standard with the aim to obtain a 28-day unconfined compressive target characterized by a 48-MPa strength. A number of trials were conducted with many configurations of cement, potable water, river sand, and coarse aggregate. The final composition of the mix had, in $1 \mathrm{~m}^{3}$ of concrete, $440 \mathrm{~kg}$ of cement, including $40 \%$ of water, $730 \mathrm{~kg}$ of river sand, and $1050 \mathrm{~kg}$ of coarse aggregate with a typical size of $10 \mathrm{~mm}$ (details in Table 1). The uniaxial compression tests were performed on 150-mm cube specimens after 28 days curing in tap water, according to the IS 456:2000 and IS 10262, and an average unconfined compressive strength of 46-51 MPa was obtained. However, the ballistic experiments have been carried out after 3-4 months of casting the specimens.

In these specimens, characterized by a square shape with span of $450 \mathrm{~mm}$ and thickness of $80 \mathrm{~mm}$, a unidirectional prestress $10 \%$ of unconfined compressive strength was introduced by pretensioning of high-strength steel wires $1700 \mathrm{MPa}$ of 4-mm diameter. The target was also reinforced with 8-mm deformed steel bars of tensile yield strength 415 MPa @ 80-mm c/c both ways with a clear cover of $15 \mathrm{~mm}$ (Figure 1(a)). The ogival-nosed (3 CRH) hard steel projectiles of mass $0.5 \mathrm{~kg}$ have been prepared on lathe machine (see Figure 1(b)).

A total number of 13 strands were inserted in the target to induce $10 \%$ prestress (see Table 2). Each strand anchored at one side and was stretched from the next end with the help of a hollow hydraulic jack. Thus, the initial stress of about $5.0 \mathrm{MPa}$ was induced in the $(450 \mathrm{~mm} \times 450 \mathrm{~mm} \times 80 \mathrm{~mm})$ concrete target. The strands were correctly positioned and fixed using steel wedges. The losses in prestress related to phenomena as elastic shortening, friction, creep, and shrinkage were also considered assuming to be $15 \%$ of the initial stress. This procedure is in accordance with the recommendation in IS 1343:2012. The method recommended by the European Committee on Concrete (1970) also includes a great number of variables, therefore achieves great flexibility, in the estimation of losses in prestressing.

The effective magnitude of prestress in the target after deducing the losses was calculated to be 4.24 MPa (see Table 2). The concrete was poured in the square steel molds, compacted with the needle vibrator, and the concrete surface was finished. The curing of concrete targets lasted 28 days and was done thanks to wet gunny bags (details in Figure 2). The wedges were then released to transfer the stress in the concrete.

\section{Geometric and FE modeling}

The geometric modeling of the concrete targets and the projectile was carried out using ABAQUS preprocessor. The square target plates of span $450 \mathrm{~mm} \times 450 \mathrm{~mm} \times 80 \mathrm{~mm}$ were modeled as threedimensional (3D) deformable continuum, and the reinforcement in the reinforced concrete targets 

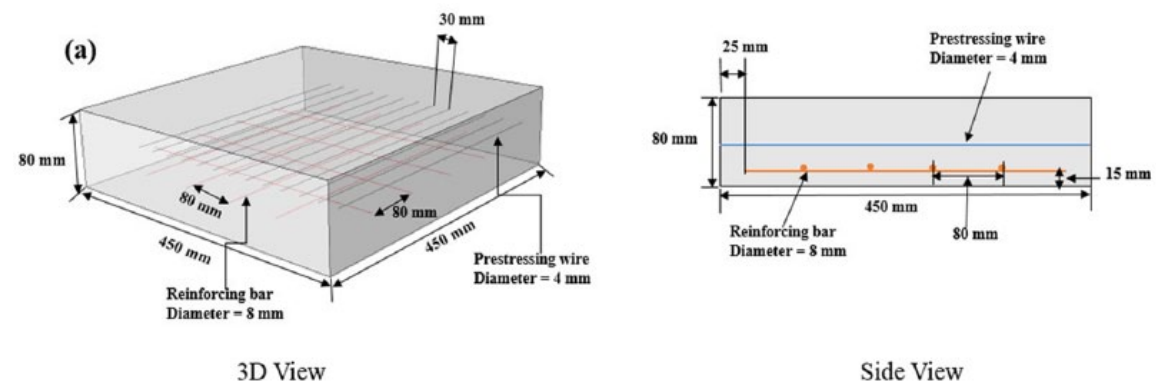

(b)

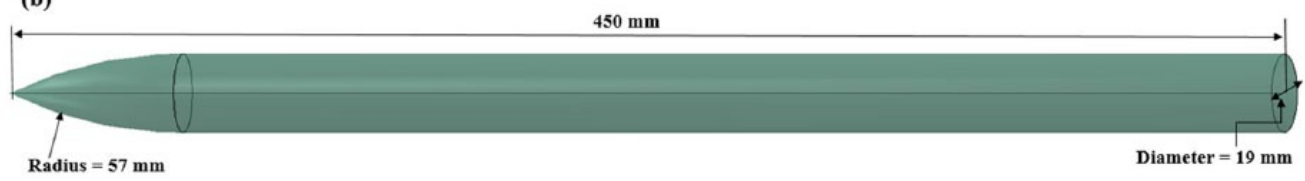

Figure I. Detailing of (a) prestressed concrete target (all dimensions in $\mathrm{mm}$ ) and (b) projectile.

Table 2. Calculation of effective stress for inducing initial prestress in the target.

\begin{tabular}{lllllll}
\hline $\begin{array}{l}\text { Target } \\
\text { thickness } \\
(\mathrm{mm})\end{array}$ & $\begin{array}{l}\text { Effective cross- } \\
\text { sectional area } \\
\left(\mathrm{mm}^{2}\right)\end{array}$ & $\begin{array}{l}\text { No. of } \\
\text { wires }\end{array}$ & $\begin{array}{l}\text { Force in } \\
\text { each wire } \\
(\mathrm{kN})\end{array}$ & $\begin{array}{l}\text { Initial stress } \\
\text { in target } \\
(\mathrm{MPa})\end{array}$ & $\begin{array}{l}\text { Losses (15\% of } \\
\text { initial stress), } \\
\mathrm{MPa}\end{array}$ & $\begin{array}{l}\text { Effective stress in } \\
\text { target }(\mathrm{MPa})=\text { initial } \\
\text { stress in target }- \text { losses }\end{array}$ \\
\hline 80 & 36,000 & 13 & 14 & 5 & 0.76 & 4.24 \\
\hline
\end{tabular}

was provided as $\varphi 8 \mathrm{~mm} @ 80-\mathrm{mm} \mathrm{c} / \mathrm{c}$ both ways. The reinforcement modeled as 3D deformable truss was replicated to form a grid at the required spacing and then inserted in the body of the concrete with a cover of $15 \mathrm{~mm}$, shown in Figure 1(a). The embedded constraints were assigned between the reinforcement and concrete to enable perfect bond between the host and the guest elements. In the prestressed concrete targets, the prestressing strands modeled as $3 \mathrm{D}$ deformable truss were inserted at the center of thickness (in one direction) to enable the development of uniform prestressing force throughout the thickness (Figure 1(a)). The cylindrical ogival-nosed projectile, with $0.5 \mathrm{~kg}$ of mass, $19-\mathrm{mm}$ diameter, and $225-\mathrm{mm}$ of length, was discretized using 3D analytical rigid shell (Figure 1(b)). A reference point was assigned to the centroid of each of the projectiles for assigning mass and rotary inertia. The contact between projectile and target was carefully considered using built-in kinematic contact algorithms. In particular, the projectile was assumed as master and nodes on the surface of the target as slaves. The friction coefficient was considered 0.05 . The projectile was also assigned surface-to-surface contact with reinforcement in reinforced concrete and the reinforcement and prestressing strands in prestressed concrete target using kinematic contact option assuming negligible friction. The edges of the target were fixed by constraining all the degree of freedom.

The meshing of the target was carefully carried out for obtaining accurate results within reasonable CPU time. The mesh convergence study was carried out by varying the size of element in the impact area of target from 0.7 to $3 \mathrm{~mm}^{3}$ with keeping unity aspect ratio and a constant element size of $5 \mathrm{~mm}^{3}$ in the outer region. The resistance of the target decreased with the decrease in the element size, and the results converged corresponding to element size of $1 \mathrm{~mm}^{3}$. The element size in the central core was, therefore, considered to be $1 \mathrm{~mm}^{3}$ in all the simulations. 3D brick elements, 


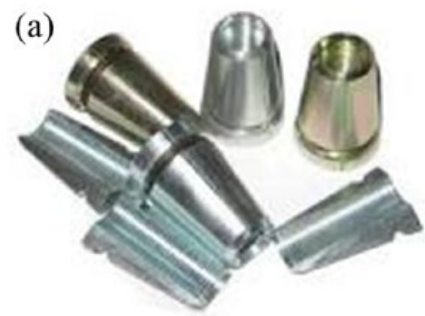

Prestressing wedges

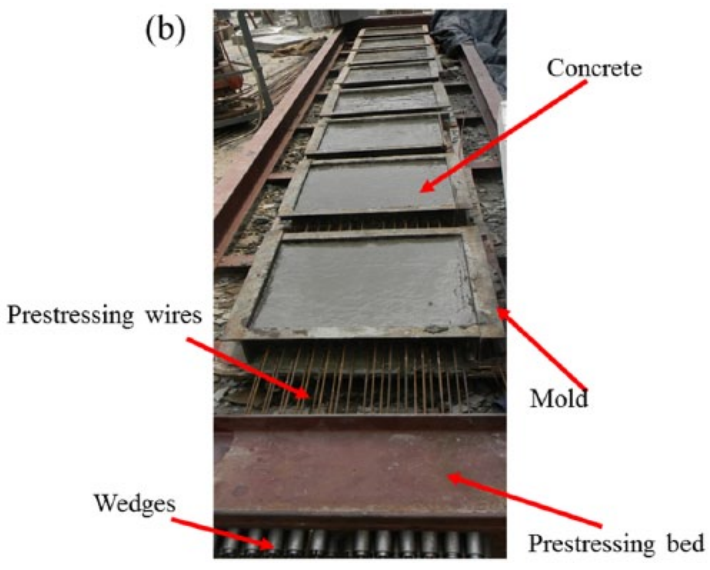

Figure 2. Details of prestressing: (a) steel wedges and (b) casting of prestressed concrete.

characterized by eight nodes and a reduced integration $(C 3 D 8 R)$, were used for meshing (see Figure 3). The number of elements in the impact and outer region was 80 and 27, respectively, resulting 391,049 number of elements of concrete. Figure 3 shows several details regarding the target discretization using FEs in the case of prestressed concrete.

\section{Constitutive modeling of concrete, reinforcement, and prestressing wires}

The FE simulations has been carried out in two steps: in the first step, initial stresses were induced in the concrete targets using static analysis in ABAQUS standard, and thereafter, the projectile impact simulations have been performed in the second step using ABAQUS/Explicit. An initial prestressing force of approximately $10 \%$ of the characteristic compressive strength of concrete was induced in the target plates (Table 2) by introducing pretension in the prestressing wire and carrying out static analysis on ABAQUS/Standard to enable complete transfer of prestress. The prestress thus induced has been incorporated as initial stress state in the target for carrying out further numerical simulation for ballistic impact on ABAQUS/Explicit code into the second step.

The concrete damaged plasticity (CDP) model was preferred for considering the condition of initial stress in the concrete. This advanced model is established on the conception of isotropic damaged elasticity in strict combination with isotropic tensile and of compressive plasticity, with the aim at representing the post-elastic behavior of concrete under conditions of tension and compression. Sadique et al. (2013) have considered CDP model into the account for incorporating the response of concrete under uniaxial compressive loads (in terms of stress-strain relations). The behavior of concrete in tension was predicted using the Hillerborg's fracture energy criterion (Hillerborg, 1985; Hillerborg et al., 1976) employing the energy required to open a unit crack area, $G_{f}$. A similar approach is also present in Sadique et al. (2013). The behavior of reinforcing steel and prestressing strands has been considered linear elastic for the simulation for inducing prestressing force in the concrete. The initial stress of magnitude 4-5 MPa (approximately $10 \%$ of concrete compressive strength) was induced in the concrete targets. The contour plots of the induced prestress in the prestressed concrete targets and corresponding tensile stress in the prestressing wires are shown in Figure 4(a) and (b), 


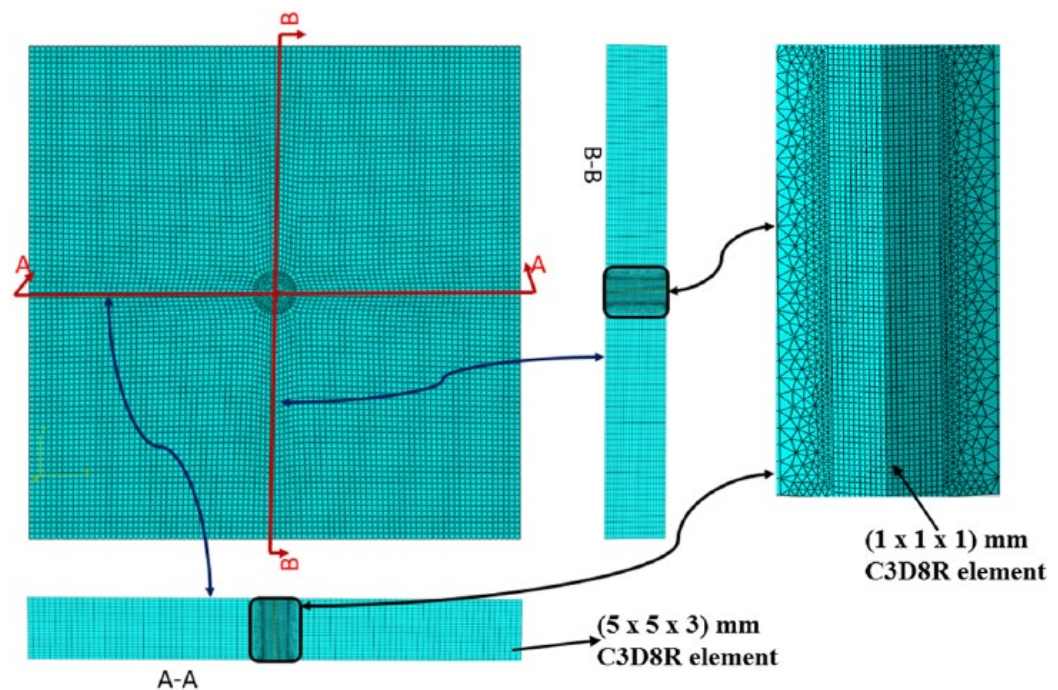

Figure 3. Plan and cross section of finite element model of 80 -mm-thick concrete target.

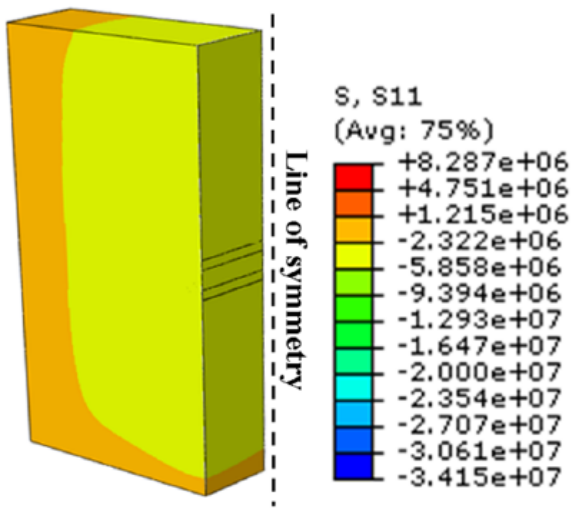

(a)

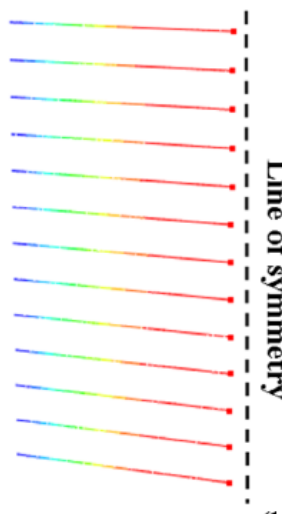

(b)
S, $\$ 11$

(Avg: 75\%)

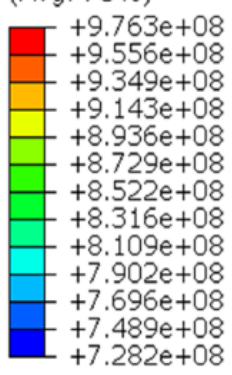

Figure 4. Symmetric half model of initially stressed concrete target: (a) concrete and (b) prestressing wires.

respectively. The stresses shown are in the direction in which the prestressing has been induced, and the negative values are indicating the induced compression into the concrete targets.

Furthermore, in second phase of simulation, the constitutive behavior for simulating the ballistic response of concrete was taken in consideration in accordance with the elasto-viscoplastic material model proposed by Holmquist-Johnson-Cook (HJC) (Holmquist et al., 1993). The HJC model calculates the normalized equivalent strength, $\sigma^{*}$, of concrete as a function of pressure and strain rate, through a simplistic uncoupled approach taking into consideration the mechanisms of cracking and compaction 


$$
\sigma^{*}=\left[A(1-D)+B P^{* N}\right]\left[1+C \ln \varepsilon^{*}\right]
$$

where $\sigma^{*}=\sigma / f_{c}^{\prime}, \sigma$ is the actual equivalent stress and $f_{c}^{\prime}$ is uniaxial compressive strength; $A$ is the cohesive strength; $D$ is material damage $(0 \leq D \leq 1) ; B$ is pressure hardening coefficient; $P^{*}=P / f^{\prime} c$ is normalized pressure; $N$ is the pressure hardening exponent; $C$ is strain rate coefficient; and $\varepsilon^{*}=\varepsilon_{e q} / \varepsilon_{0}$ is the normalized strain rate, $\varepsilon_{e q}$ is equivalent strain rate and $\varepsilon_{0}$ is reference strain rate. The scalar damage formulation employed in the model accumulates the damage from equivalent plastic strain as well as the equivalent plastic volumetric strain

$$
D=\sum\left[\frac{\Delta \varepsilon_{p}+\Delta \mu_{p}}{\varepsilon_{p}^{f}+\mu_{p}^{f}}\right]
$$

where $\Delta \varepsilon_{p}$ and $\Delta \mu_{p}$ are incremental plastic strain and incremental plastic volumetric strain caused by the shear deformation and the effect of crushing of the air voids in the concrete, respectively. $\varepsilon_{p}^{f}+\mu_{p}^{f}$ is the plastic strain to fracture defined as

$$
\varepsilon_{p}^{f}+\mu_{p}^{f}=D 1\left(P^{*}+T^{*}\right)^{D 2}
$$

where $D 1$ and $D 2$ are damage parameters while $T^{*}=T / f^{\prime} c$ represents the normalized maximum tensile hydrostatic pressure when $T$ is the maximum value of the tensile hydrostatic pressure the concrete is able to tolerate. The hydrostatic pressure volume relationship is separated into a linear elastic, plastic (with gradual compression of air voids), and fully dense (air void completely removed) material response. The material parameters employed in this study for 48-MPa concrete were taken from (Holmquist et al., 1993).

The constitutive behavior of reinforcement and prestressing strands during ballistic impact was incorporated using the Johnson-Cook elasto-viscoplastic material model (Johnson and Cook, 1983,1985 ) The model is best suited for metals and assumes the equivalent von Mises stress $\bar{\sigma}$ in the following form

$$
\bar{\sigma}\left(\bar{\varepsilon}^{p l}, \dot{\bar{\varepsilon}}^{p l}, \hat{T}\right)=\left[A+B\left(\bar{\varepsilon}^{p l}\right)^{n}\right]\left[1+C \ln \left(\frac{\dot{\bar{\varepsilon}}^{p l}}{\dot{\varepsilon}_{0}}\right)\right]\left[1-\hat{T}^{m}\right]
$$

where $A, B, n, C$, and $m$ are material parameters; $\bar{\varepsilon}^{p l}$ is equivalent plastic strain; $\dot{\bar{\varepsilon}}^{p l}$ is equivalent plastic strain rate; $\dot{\varepsilon}_{0}$ is a reference strain rate; and $\hat{T}$ is non-dimensional temperature defined as

$$
\hat{T}=\left(T-T_{0}\right) /\left(T_{m e l t}-T_{0}\right), \quad T_{0} \leq T \leq T_{\text {melt }}
$$

where $T$ is the current temperature, $T_{\text {melt }}$ is the melting temperature, and $T_{0}$ is the room temperature. The failure is considered to happen when $D$, the damage parameter, exceeds the unity

$$
D\left(\bar{\varepsilon}^{P}, \dot{\bar{\varepsilon}}^{P}, T, \sigma^{*}\right)=\sum \frac{\Delta \bar{\varepsilon}^{P}}{\bar{\varepsilon}_{f}^{P}\left(\dot{\bar{\varepsilon}}^{P}, T, \sigma^{*}\right)}
$$




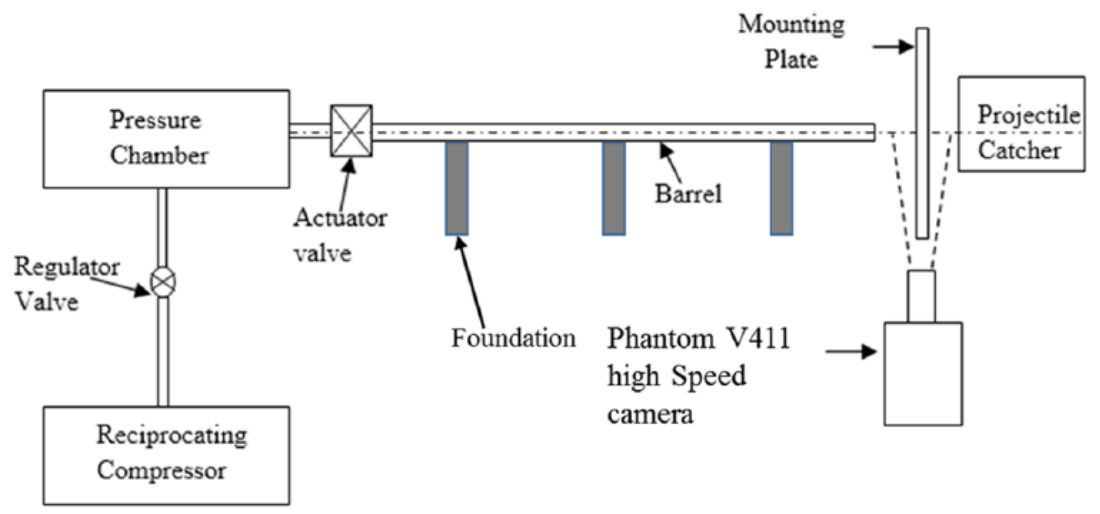

Figure 5. Graphical illustration of experimental setup of pneumatic gun.

where $\Delta \bar{\varepsilon}^{P}$ represents the increment in the accumulation of the equivalent plastic strain related to a cycle of integration and $\bar{\varepsilon}_{f}^{P}$ is the equivalent plastic failure strain. This model of fracture, initially proposed by Johnson and Cook (1983) and Holmquist et al. (1993), permits to take into consideration the combined effects on the failure strain of a 3D state of stress, strain rate, and finally, the temperature.

The equivalent plastic failure strain, $\bar{\varepsilon}_{f}^{p l}$, is expressed as

$$
\bar{\varepsilon}_{f}^{p l}\left(\frac{\sigma_{m}}{\bar{\sigma}}, \dot{\bar{\varepsilon}}^{p l}, \hat{T}\right)=\left[D_{1}+D_{2} \exp \left(D_{3} \frac{\sigma_{m}}{\bar{\sigma}}\right)\right]\left[1+D_{4} \ln \left(\frac{\dot{\bar{\varepsilon}}^{p l}}{\dot{\varepsilon}_{0}}\right)\right]\left[1+D_{5} \hat{T}\right]
$$

where the difference $D_{1}-D_{5}$ basically represents a parameter related to the material properties while $\sigma_{m} / \bar{\sigma}$ is the triaxiality ratio of stress when $\sigma_{m}$ symbolizes the average stress. The material properties of reinforcement were taken from Borvik et al. (2001).

The strength of the concrete plates was significantly lesser than that of the hard steel projectile. Hence, the projectile was modeled as a non-deformable or rigid body. During experiments, the deformation of projectile was found to be insignificant. However, some scratches were noticed near the nose of the projectiles. Hence, this assumption was found to be justified.

\section{Ballistic experiments and FE simulations}

The projectile impact experiments and FE simulations were performed to obtain the ballistic characteristics of prestressed concrete targets. The impact experiments carried out with the help of pneumatic gun capable to launch a $0.5-\mathrm{kg}$ projectile at a speed of $280 \mathrm{~m} / \mathrm{s}$. The barrel was $18-\mathrm{m}$ long in the way to enable an adequate acceleration of the projectile for obtaining the necessary speed. The trajectory was simplified considering the projectile with an orthogonal impact on the target (see Figure 5). The projectile was impacted at center of the target; however, the target was kept fixed at all the edges. Impacts occurred in a range between 90 and $225 \mathrm{~m} / \mathrm{s}$ of projectile impact velocities. A high-speed video camera (Vision Research Phantom V411) was used to record the projectile striking and residual velocities. The camera frame rate was kept in the range of 15,00020,000 to record the impact experiments. The projectile after perforation was safely collected in a robust steel box placed $1.5 \mathrm{~m}$ behind the target. 

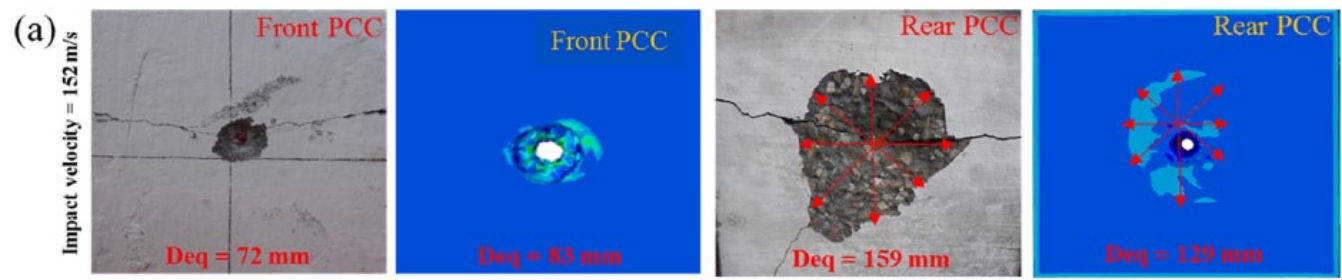

(b)
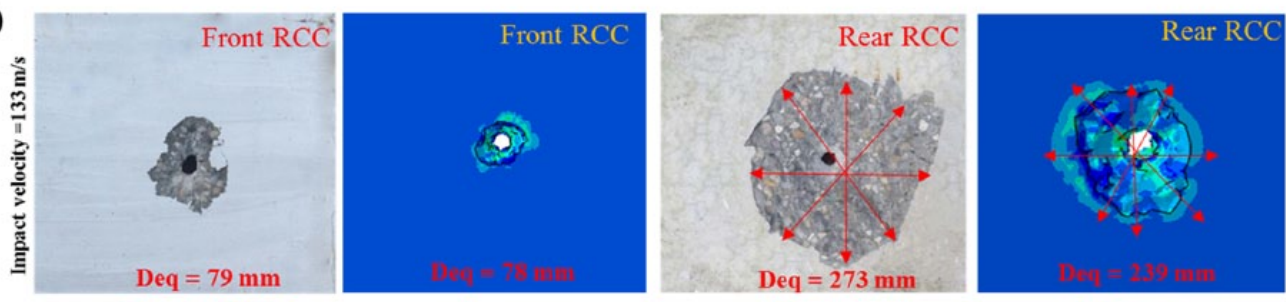

(c)
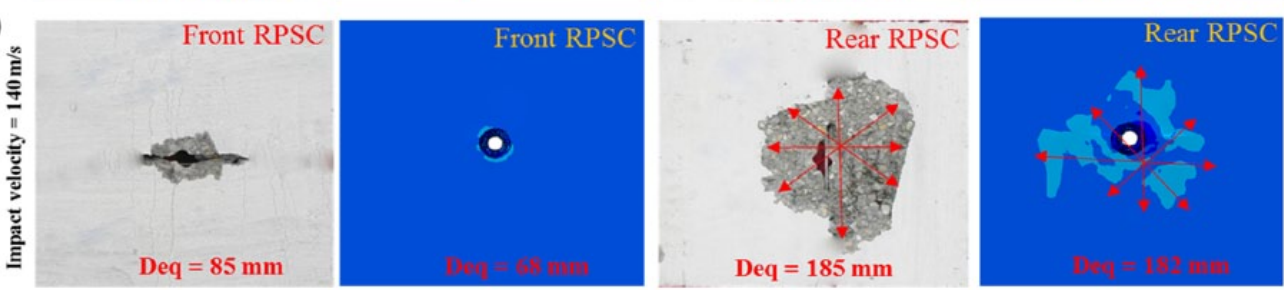

Figure 6. Tested specimens of 80-mm thickness: (a) plain, (b) reinforced, and (c) prestressed concrete targets.

The numerical simulations were able to strictly predict several aspects of the impact on the prestressed concrete as the failure modes, residual speeds, and ballistic limits of targets. The acquired impact and residual projectile velocities and failure modes of prestressed concrete targets were compared with that of the plain and reinforced concrete targets obtained in the previous experimental study (Rajput et al., 2017a). The failure modes of the targets were found to be dependent upon the type of concrete and the incidence velocity of projectile. Targets in plain concrete showed conditions of brittle failure. Thick radial cracks, 3- to 7-mm wide, originating from the impact location, developed across the target thickness and traversed over entire span leading to brittle failure of the target. In case of reinforced and prestressed concrete targets, there was no observable cracks could be found in the experiments. The FE simulation could not be able to predict tensile cracking in plain concrete targets due to the limitation of the HJC model to adequately address the tensile cracking in concrete (see Figure 6).

\section{Quantification of damage and ballistic resistance}

The equivalent diameter $\left(D_{e q}\right)$ of the front and rear surface crater was defined as the average value between the four diameters measured in different orientations (see Figure 6). The details of measures for equivalent diameters are reported in Table 3. It can be noticed that the front surface shows a low level of damage, and additionally, its variation with respect to impact speed and concrete properties was negligible. On the contrary, the impact speed had a significant influence on the rear surface crater. For a given concrete, the diameter of the crater, in the case of rear surface, decreased with the increase in the projectile speed. Furthermore, for a specific incidence velocity, higher size 


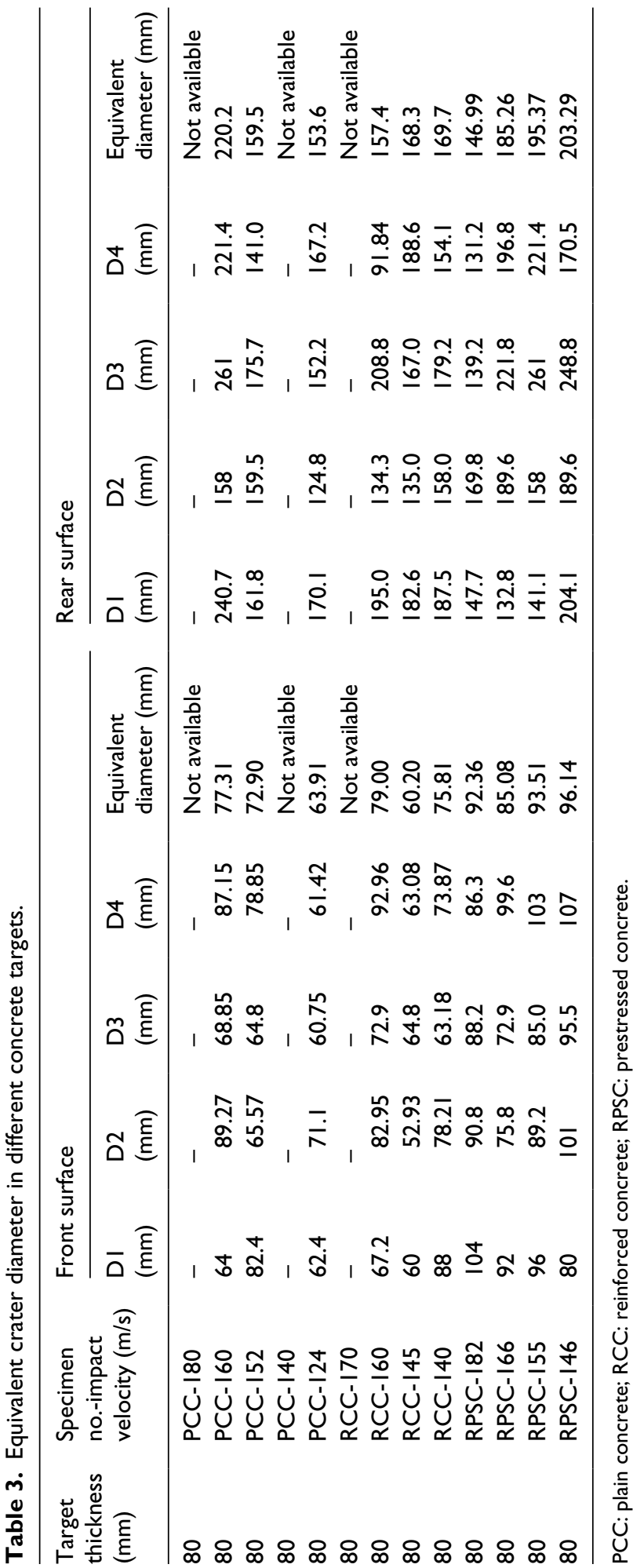


Table 4. Volume eroded in the case of different concrete targets.

\begin{tabular}{llll}
\hline Target thickness $(\mathrm{mm})$ & Specimen no. & Front surface $\left(\times 10^{3} \mathrm{~mm}^{3}\right)$ & Rear surface $\left(\times 10^{3} \mathrm{~mm}^{3}\right)$ \\
\hline 80 & PCC-180 & Not available & Not available \\
80 & PCC-160 & 54.4 & 309.4 \\
80 & PCC-152 & Not available & Not available \\
80 & PCC-140 & 71.4 & 424.1 \\
80 & PCC-124 & 96.9 & 589.9 \\
80 & RCC-170 & Not available & Not available \\
80 & RCC-160 & 50.1 & 249.9 \\
80 & RCC-145 & 28.9 & 385.9 \\
80 & RCC-140 & 28.9 & 521.9 \\
80 & RCC-133 & Not available & Not available \\
80 & RPSC-182 & 28 & 275 \\
80 & RPSC-166 & 33 & 288 \\
80 & RPSC-155 & 44 & 313 \\
80 & RPSC-146 & 45 & 334 \\
\hline
\end{tabular}

PCC: plain concrete; RCC: reinforced concrete; RPSC: prestressed concrete.

in the crater was recognized in the case of prestressed concrete target, followed by reinforced and plain concrete cases. However, it should be noticed that the depth of rear surface crater was found shallow (in depth) for prestressed concrete target.

In order to provide additional information regarding the damage induced in the different concrete targets (e.g. in terms of eroded material), the volume of craters was obtained for each target (see Table 4).

The volume of spalling has been noticed to be rather low, and additionally, its variability could not be appreciated with respect to the projectile speed and the type of concrete. Furthermore, the volume of scabbing has shown to be more influenced by the incidental velocity than by the type of concrete. In particular, this volume increased with the decrease in the incidence velocity. The volume of scabbing was highest in the plain concrete, followed by reinforced and $10 \%$ prestressed concrete (see Figure 7(a) to (c)).

The FE simulations have predicted failure modes, crater diameter, and residual velocities of projectile in agreement with the residual velocities of the projectile obtained through ballistic impact experiments.

The impact and residual velocities were obtained using a high-speed video camera, as shown in Table 5. The actual and predicted velocities of the projectile impacting on the target are plotted in Figure 8 . The overall resistance of the concrete to the ballistic impacts has been measured and increased with the decrease in the impact speed (see Figure 8). This effect was found most relevant for prestressed concrete followed by reinforced and plain concrete, respectively. The ballistic limits of the concretes under investigation have been obtained as the average of the highest velocity giving partial penetration and the lowest velocity giving a complete perforation of the target (see Table 6). The ballistic limit of prestressed concrete targets measured through the experiments was found to be $10.2 \%$ and $14 \%$ higher than the reinforced and plain concrete targets, respectively. The energy absorption capacity of the prestressed and reinforced concrete targets was found to be $30 \%$ and $7 \%$ higher than that of the plain concrete target (see Table 6).

The initial prestressing has proved to be effective in minimizing the damage and improving ductility of concrete. It is noteworthy that the damaging effect of the projectile impact on the concrete is due to the presence of tensile component in the stresses. Besides, since the presence of an 
(a)

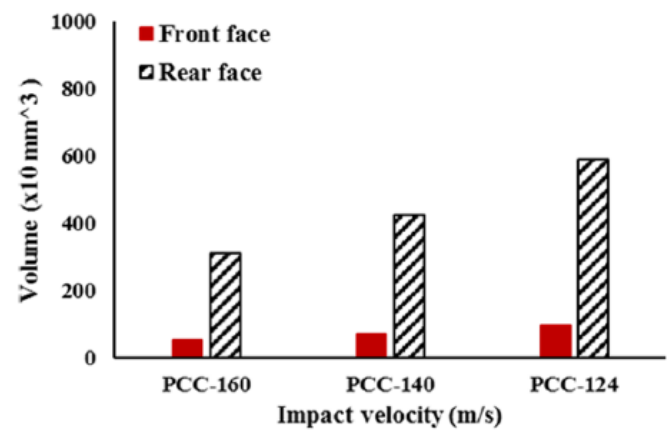

(b)

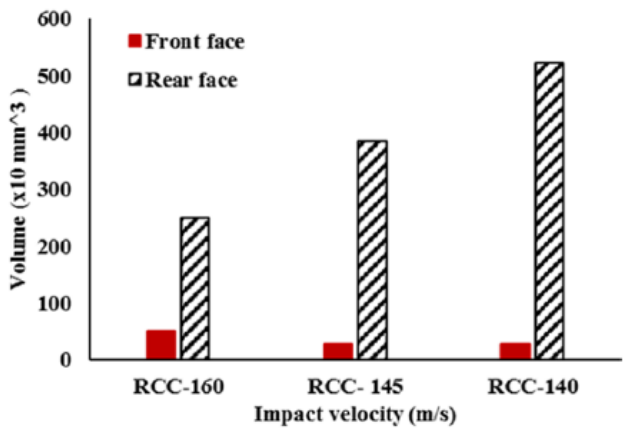

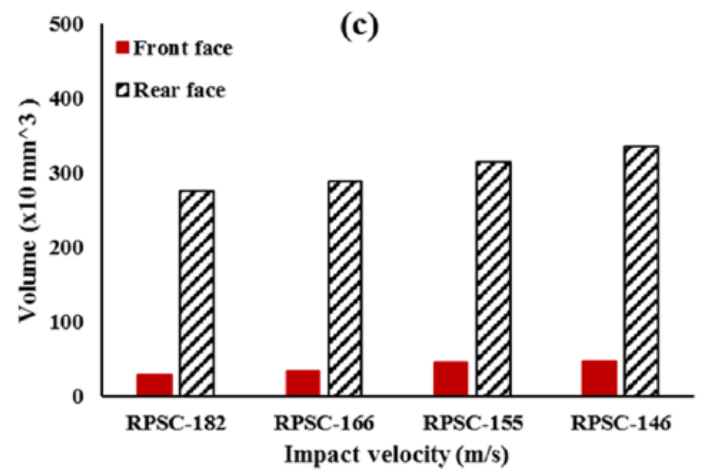

Figure 7. Scabbing and spalling effect for a $80-\mathrm{mm}$ target in the case of (a) plain, (b) reinforced, and (c) prestressed concrete.

Table 5. Incidence and residual projectile velocities for different concrete types and target thicknesses.

\begin{tabular}{llll}
\hline Type of concrete & $\begin{array}{l}\text { Initial velocity } \\
(\mathrm{m} / \mathrm{s})\end{array}$ & \multicolumn{2}{l}{ Residual velocity $(\mathrm{m} / \mathrm{s})$} \\
\cline { 3 - 4 } & & Experimental & Numerical \\
\hline Plain concrete (PCC) & 180 & 76 & 90 \\
& 160 & 50 & 61 \\
& 152 & 38 & 42 \\
& 140 & - & 28 \\
& 135 & 0 & 40 \\
& 124 & - & 13 \\
Reinforced concrete & 122 & - & 12 \\
(RCC) & 120 & 59 & 0 \\
& 170 & 42 & 66 \\
& 160 & 28 & 55 \\
& 145 & 15 & 20 \\
& 140 & - & 8 \\
& 135 & 0 & 0 \\
\hline
\end{tabular}


Table 5. (Continued)

\begin{tabular}{llll}
\hline Type of concrete & $\begin{array}{l}\text { Initial velocity } \\
(\mathrm{m} / \mathrm{s})\end{array}$ & \multicolumn{2}{l}{ Residual velocity $(\mathrm{m} / \mathrm{s})$} \\
\cline { 3 - 4 } & & Experimental & Numerical \\
\hline Prestressed concrete & 182 & 62 & 71 \\
(RPSC) & 166 & 32 & 44 \\
& 155 & 14 & 26 \\
& 146 & 0 & 11 \\
& 140 & - & 0 \\
\hline
\end{tabular}
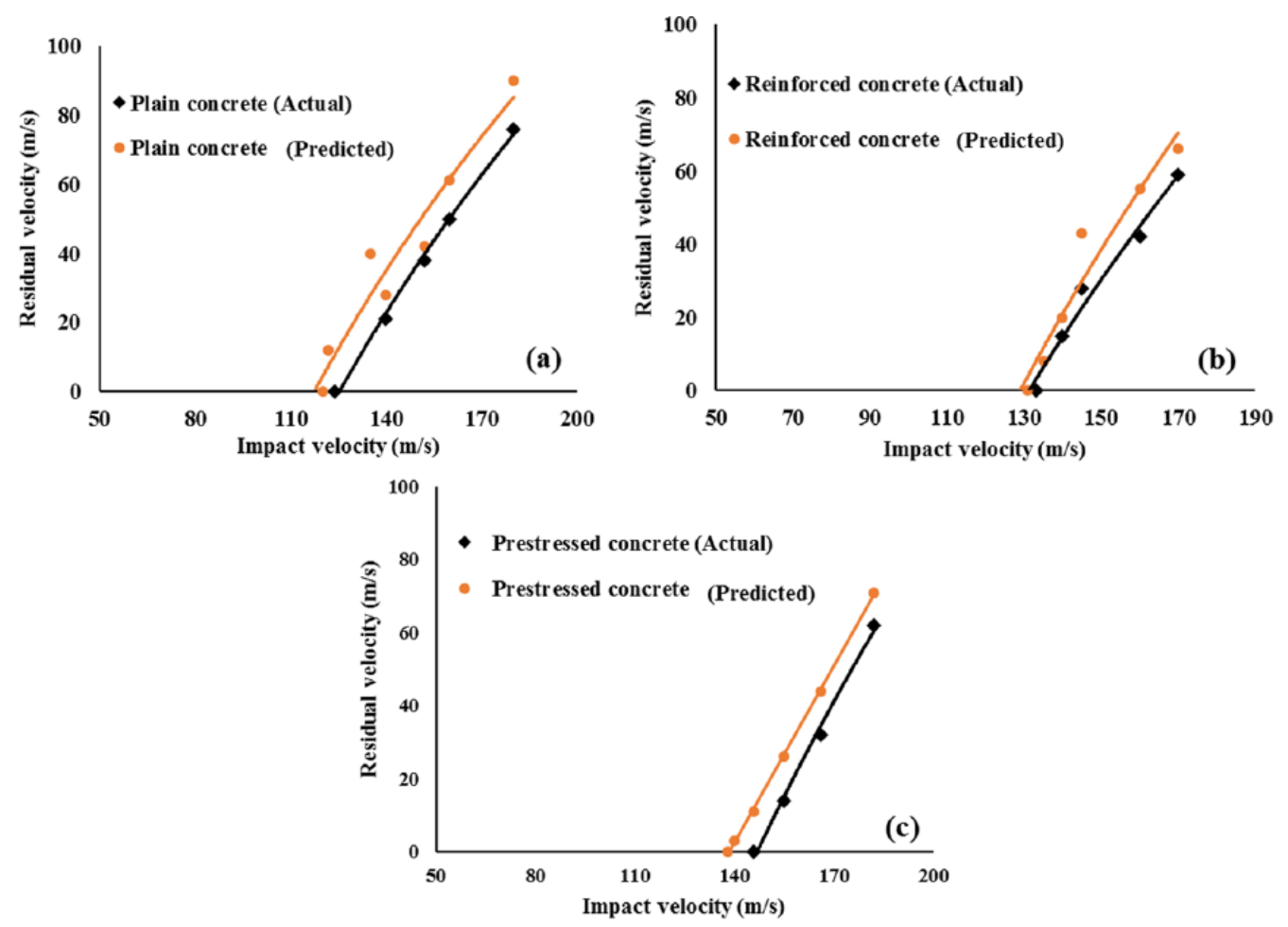

Figure 8. Comparison between actual and predicted residual velocities of projectiles subjected to: (a) plain, (b) reinforced, and (c) prestressed concrete.

Table 6. Calculated ballistic limit from the experiments.

\begin{tabular}{llllllll}
\hline \multirow{2}{*}{ Target thickness $(\mathrm{mm})$} & \multicolumn{3}{l}{ Ballistic limit $(\mathrm{m} / \mathrm{s})$} & & \multicolumn{3}{l}{ Energy absorbed $(\mathrm{J})$} \\
\cline { 2 - 3 } & Actual & Predicted & Error $(\%)$ & & Actual & Predicted & Error (\%) \\
\hline Plain concrete & 132 & 121 & 8.3 & & 4356 & 3660 & 15.9 \\
Reinforced concrete & 136.5 & 133 & 2.5 & & 4658 & 4422 & 5.0 \\
Prestressed concrete & 150.5 & 143 & 4.9 & & 5662 & 5112 & 9.7 \\
\hline
\end{tabular}


initial compressive stress, the magnitude of tensile stress decreased. Therefore, the prestressed concrete underwent comparatively lesser damage and offered higher ballistic resistance in comparison with reinforced and plain concrete targets.

\section{Conclusion}

The projectile impact experiments have been performed on the prestressed concrete (48 MPa) targets and compared with the experiments earlier carried by (Fragassa, 2016; Pavlovic and Fragassa, 2016) on the plain and reinforced concrete targets. The ballistic limit of prestressed, reinforced, and plain concrete target was predicted with the deviation of $5 \%, 3 \%$, and $8 \%$ of actual results, respectively. Due to the introduction of prestresses in the concrete plates, there is a huge decrease noticed in the volume of scabbing. The magnitude of volume that was ejected from the concrete target was found to be decreased with the increasing projectile impact velocity.

For given projectile impact velocity, the equivalent size of crater was found higher in case of prestressed concrete; however, the depth of crater was found shallow in comparison with targets in reinforced or plain concrete. Hence, the initial prestressing has proved to be effective in minimizing the damage and improving ductility of concrete. It is also found that the highest ballistic resistance was offered by the prestressed concrete target, followed by reinforced and plain concrete targets.

\section{Declaration of conflicting interests}

The author(s) declared no potential conflicts of interest with respect to the research, authorship, and/or publication of this article.

\section{Funding}

The author(s) disclosed receipt of the following financial support for the research, authorship, and/or publication of this article: This work was supported by the Science and Engineering Research Board, Department of Science and Technology, India, through the research grant no. SB/S3/CEE/0032/2014 for carrying out this study.

\section{References}

Adikary SD, Li B and Fujikake K (2015) Low velocity impact response of reinforced concrete beams: experimental and numerical investigation. International Journal of Protective Structures 6(1): 81-111.

Borvik T, Hopperstad OS, Berstad T, et al. (2001) Numerical simulation of plugging failure in ballistic penetration. International Journal of Solids and Structures 38: 6241-6264.

Chen W, Hao H and Chen S (2015) Numerical analysis of prestressed reinforced concrete beam subjected to blast loading. Materials \& Design 65: 662-674.

Delhomme F, Mommessin M, Mougin JP, et al. (2007) Damage mechanisms of a reinforced concrete rockshed slab impacted by blocks. Journal of Structural Engineering 133(10): 1426-1433.

European Committee on Concrete (1970) International Recommendations for the Design and Construction of Concrete Structures. Belgium: European Committee on Concrete.

Forrestal MJ, Altman BS, Cargile JD, et al. (1994) An empirical equation for penetration depth of ogive-nose projectiles into concrete targets. International Journal of Impact Engineering 15(4): 395-405.

Fragassa C (2016) Modelling the viscoelastic response of ceramic materials by commercial finite elements codes. FME Transactions 44: 58-64.

Hanchak SJ, Forrestal MJ, Young ER, et al. (1992) Perforation of concrete slabs with $48 \mathrm{MPa}$ (7 ksi) and 140 $\mathrm{MPa}$ (20 ksi) unconfined compressive strengths. International Journal of Impact Engineering 12: 1-7.

Hao Y, Hao H, Li, et al. (2010) Numerical analysis of lateral inertial confinement effects on impact test of concrete compressive material properties. International Journal of Protective Structures 1(1): 145-167. 
Hillerborg A (1985) Results of three comparative test series for determining the fracture energy $\mathrm{G}_{\mathrm{F}}$ of concrete. Materials and Structures 18: 407-413.

Hillerborg A, Modeer M and Petersson PE (1976) Analysis of crack formation and crack growth in concrete by means of fracture mechanics and finite elements. Cement and Concrete Research 6(6): 773-782.

Holmquist TJ, Johnson GR and Cook WH (1993) A computational constitutive model for concrete subjected to large strains, high strain rates and high pressures. In: Proceedings of 14th international symposium on Ballistics, Quebec, Canada, September, 1993. pp. 591-600.

Ishikawa N, Katsuki S and Takemoto K (2002) Incremental impact test and simulation of prestressed concrete beam. Struct Mater 2002;11:489-498.

Johnson GR and Cook WH (1983) A constitutive model and data for metals subjected to large strains, high strain rates and high temperatures. In: Proceedings of the seventh international symposium on ballistics, The Hague, The Netherlands, 1983, pp. 1-7.

Johnson GR and Cook WH (1985) Fracture characteristics of three metals subjected to various strains, strain rates, temperatures and pressures. Engineering Fracture Mechanics 21: 31-48.

Kaewunruen S and Remennikov AM (2009) Progressive failure of prestressed concrete sleepers under multiple high-intensity impact loads. Engineering Structures 31(10): 2460-2473.

Kaewunruen S and Remennikov AM (2010) Dynamic crack propagations in prestressed concrete sleepers in railway track systems subjected to severe impact loads. Journal of Structural Engineering 136(6): 749-754.

Kaewunruen S and Remennikov AM (2011) Experiments into impact behaviour of railway prestressed concrete sleepers. Engineering Failure Analysis 18(8): 2305-2315.

Li QM, Reid SR, Wen HM, et al. (2005) Local impact effects of hard missiles on concrete targets. International Journal of Impact Engineering 32: 224-284.

Liu H and Ning J (2009) Mechanical behavior of reinforced concrete subjected to impact loading. Mechanics of Materials 41: 1298-1308.

Pavlovic A and Fragassa C (2016) Modelling the viscoelasticity of ceramic tiles by finite element. In: Proceedings of the 8th conference on times of polymers \& composites, vol. 1736, Ischia, 19-23 June, p. 4949749. College Park, MD: American Institute of Physics.

Pavlovic A, Fragassa C and Disic A (2017) Comparative numerical and experimental study of projectile impact on reinforced concrete. Composites Part B: Engineering 108: 122-130.

Rajput A, Iqbal MA and Bhargava P (2017a) Experimental and numerical study of concrete targets under high rate of loading. Procedia Engineering 173: 130-137.

Rajput A, Iqbal MA and Pavlovic A (2017b) Response of initially stressed concrete targets under high rate of loading. FME Transactions 45: 517-523.

Sadique MR, Iqbal MA and Bhargava P (2013) Nuclear containment structure subjected to commercial and fighter aircraft crash. Nuclear Engineering and Design 260: 30-46.

Shirai T, Kambayashi A, Ohno T, et al. (1997) Experiment and numerical simulation of double-layered RC plates under impact loadings. Nuclear Engineering and Design 176: 195-205.

Warren TL, Forrestal MJ and Randles PW (2014) Evaluation of large amplitude deceleration data from projectile penetration into concrete targets. Experimental Mechanics 54: 241-253.

Warren TL, Fossum AF and Frew DJ (2004) Penetration into low-strength (23 MPa) concrete: target characterization and simulations. International Journal of Impact Engineering 30: 477-503.

Wen HM and Yang Y (2014) A note on the deep penetration of projectiles into concrete. International Journal of Impact Engineering 66: 1-4.

Xiang Y and Nianzhi W (1994) Effect of loading rate and support conditions on the mode of failure of prestressed concrete railroad ties subjected to impact loading. Cement and Concrete Research 24(7): $1286-1298$. 